International Journal of Engineering \& Technology, $7(2.28)(2018) 38-46$
International Journal of Engineering \& Technology
SPC
Website: www.sciencepubco.com/index.php/IJET
Research paper

\title{
Implementing Quick Response Manufacturing to Improve Delivery Performance in an ETO Company
}

\author{
Bong Cheng Siong ${ }^{1 *}$, Chong Kuan Eng² \\ 1,2 Advanced Manufacturing Center, Faculty of Manufacturing Engineering, \\ Universiti Teknikal Malaysia Melaka, 76100 Durian Tunggal, Melaka. \\ *Email: bongcs@gmail.com
}

\begin{abstract}
As the pressure is increasing to compete with others to get customer orders in the global market, companies are struggling to build up competitive advantages that are hard to imitate. The trend shows more and more customers demand faster product delivery in the last decade. The Quick Response Manufacturing (QRM) approach provides significant benefits to engineer-to-order (ETO) companies through its focus on lead time reduction. A precision parts manufacturer was selected as case study to what extent QRM is a suitable solution to improve the delivery performance. This paper describes the implementation of the QRM concepts and illustrates how they were deciphered into practices that streamline the process across the organization. The study measures the effectiveness of the QRM framework through its ability to achieve better performance through concurrently reducing manufacturing critical-path time, lowering capacity utilization level and increasing throughput.
\end{abstract}

Keywords: Quick Response Manufacturing; engineer-to-order; case study; utilization; lead time

\section{Introduction}

Today it is still challenging for companies that supply low-volume, high-mix and custom-engineered products, such as Engineer-toOrder (ETO) precision parts manufacturers to meet the speed of delivery that desired by the customers. Such custom made manufacturing has to deal with dynamic, uncertain and complex situations almost every day [1]. The customer demand is fluctuated and unpredictable. Products which mostly depend on customer preferences, are fabricated via different routes with varied processing times. These factors always lead to the moving bottlenecks, planning and scheduling difficulties that result in long lead times and failure to meet on-time delivery [1].

More recently, the pressure has become pinnacle as globalization causes competition to increase where more and more customers demand faster product delivery. This emerging scene coincides with the foresight exists thirty year ago when Stalk [2] described Time is the next source of competitive advantage in the new century after cost reduction was the competitive weapon in the ' 70 s and quality in the ' $80 \mathrm{~s}$. To outbeat the competitors in the market, companies must develop competences that are difficult to imitate [3]. Suri [4] has then introduced Quick Response Manufacturing (QRM) that helped companies to gain the competitive advantage by pursuing faster product delivery.

QRM is a manufacturing control strategy that has found use in many situations where product variety can be high. Its goal is to increase throughput and one of the outcomes is to reduce lead times across all operations within the company, external as well as internal [4]. The big-picture idea is to deliver orders to customers more quickly, reduce cost and improve quality [5]. From the manufacturing paradigms comparison studied [6], QRM seems to be well-suited for companies that ETO most of all of their product line while carrying little inventory.

\section{Literature Review}

Offering custom-engineered products is a strategic decision of companies to distinguish themselves from other companies. This section explains the definition of customization, production challenges and delivery performance issue actually found in ETO companies. Hereafter, it will be explained what solution QRM provides to solve these problems.

\subsection{Defining Customization}

Customization is employed as a strategic decision [3] in the companies where production is initiated only after the order is officially received from the customers [7]. There are different levels of customization that companies can pursue [8]. Lampel and Mintzberg [9] distinguished five levels of customization as summarized in Table 1. From the tabled strategies and description, the Pure Customization is commonly seen in ETO companies.

\subsection{Understanding the Challenges of ETO Companies}

The competitive advantage and also the main challenge of ETO companies is how can the order being executed and completed within the shortest cycle time [4][10][11]. However, controlling production processes is still one of the major problematic areas in ETO companies which produce precision parts today. This type of production plants is concerned with the engineering and production of high precision parts based on customer requirement. 
Table 1: Levels of Customization

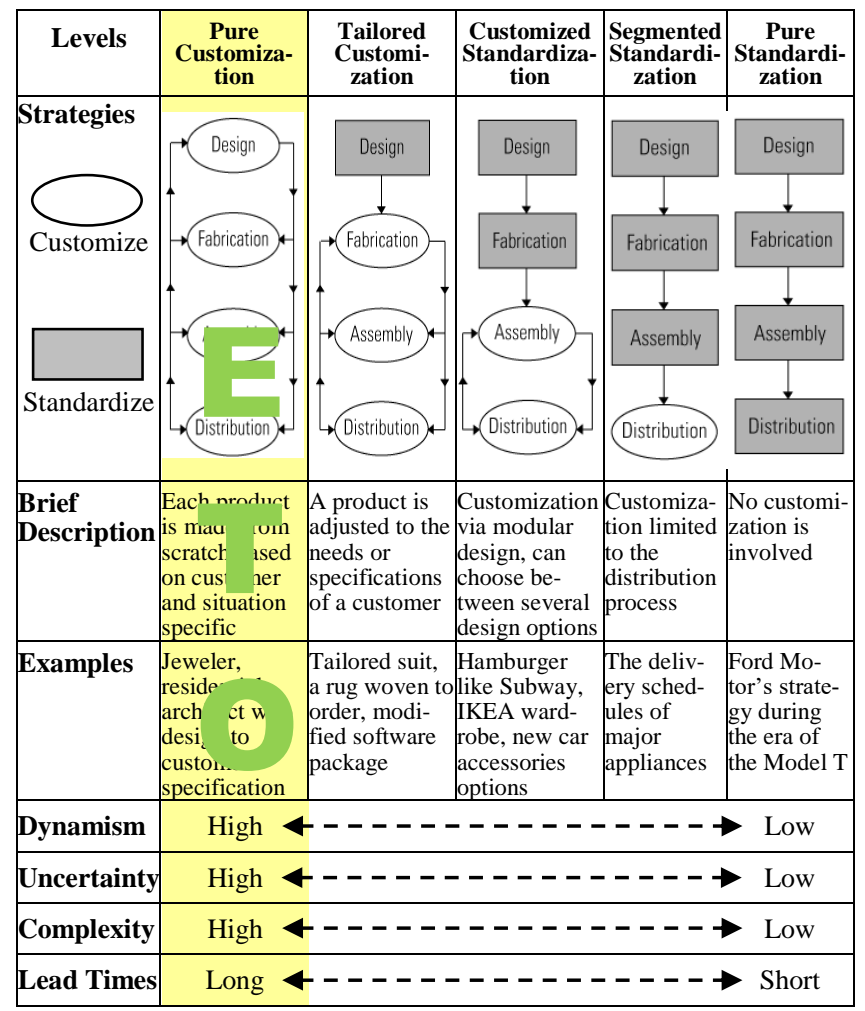

This industry operates in an environment (market as well as production processes) which can be characterized as being dynamic, uncertain and complex [1], due to unpredictable sales volumes and unknown product specifications for the future orders. The degree of each characteristic which varied for different level of customization is depicted in Table 1. This led to why the most often mentioned ETO performance measures is the Service Level [11], which is defined by how quick a company can deliver products to the customer and the accuracy of their delivery, i.e. reliability [12]. This is calculated by the amount of orders that are being delivered on time and also called on time delivery (OTD) that has direct relationship with the lead time measured in many companies. The long lead time which is often seen in the pure customization companies, tend to have a low OTD performance.

Figure 1 explains the common scenario of an ETO company experiences using an iceberg analogy. The existence of dynamism, uncertainty and complexity or high variability is something natural, unseen and imperishable in the ETO business which adopted as common causes. This is why ETO companies often struggle with certain challenges in planning sustainability, scheduling robustness and moving bottleneck that result in long lead times. This leads to failures in meeting the committed due dates or OTD. In order to find out the special cause(s), first must understand the production system and deficiencies of handling the challenges in ETO companies that explained in the next section.

\subsection{Identifying the Special Causes of OTD Failure}

ETO companies continue to make every effort to fulfil OTD of their products to the customer. Unless there's an ample capacity available in the line, otherwise the practice of early delivery shouldn't be encouraged as it takes up machines need for orders that might now be delivered late. The ideal situation would be orders are delivered as close to the due date as possible [13]. Four potential causes of late deliveries have been distinguished by New [13]:-

- Insufficient lead-time allowance. Despite good control over inlet and scheduling, performance is poor. This indicates that the promised due dates to customer, including the safety net are insufficient. This could also be due to overload with no input control.

- Pre-production delays. This is seen when problems occur with pre-production delays on some batches (like awaiting drawings, material, tooling, etc), while other batches continue through uninterrupted.

- Sequencing problem. This means lack of control in sequencing of jobs. If this is happening within a company, the scheduling system should be investigated.

- Shop floor overload. This is happened in situations where more orders are accepted than can be handled. The overloaded orders are either kept outside the shop floor or long queue in front of the high loading equipment.

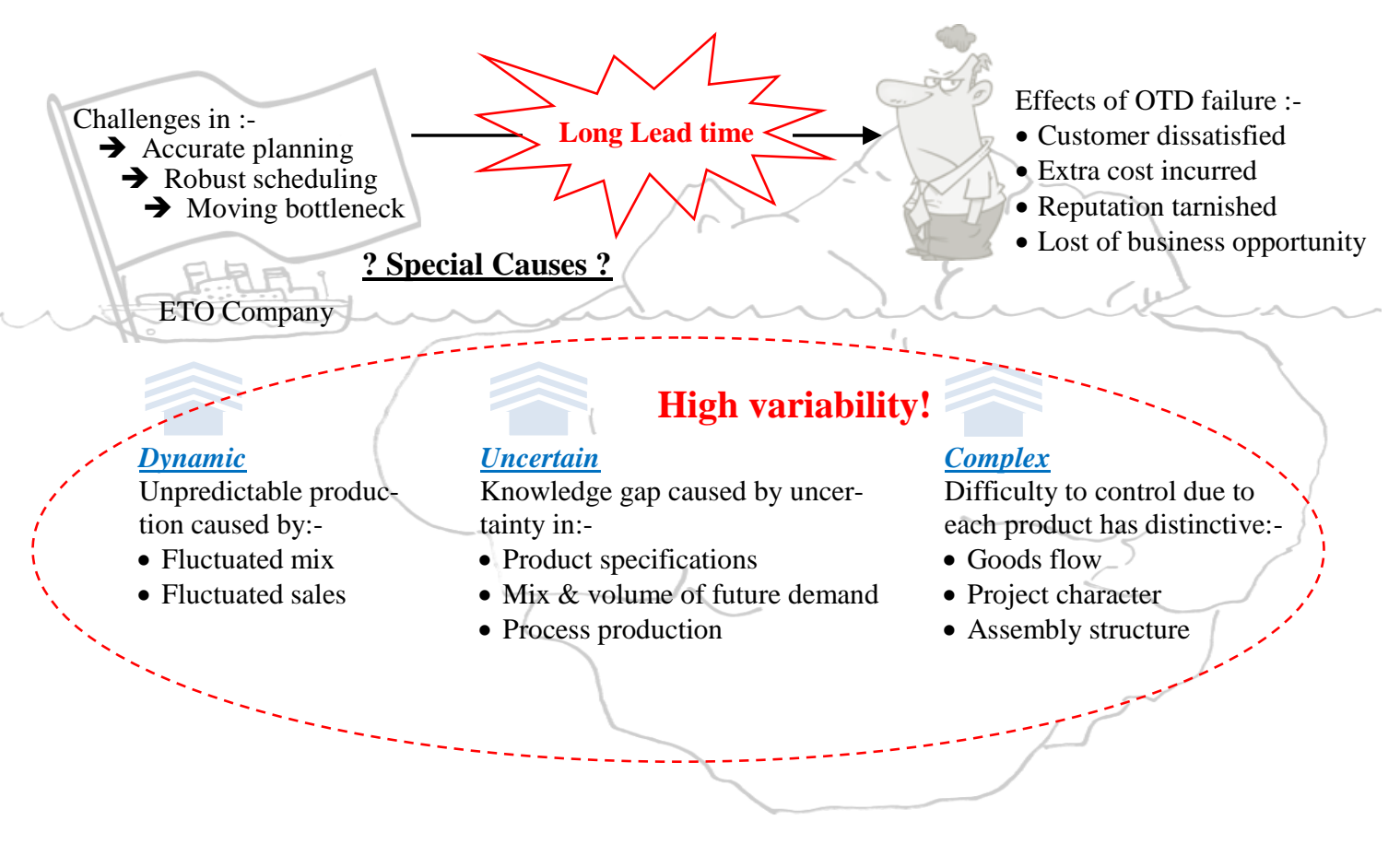

Figure 1: Challenges of ETO Companies 
Figure 2 reveals the occurring point of each cause above that is commonly found on the typical process flow of ETO companies [14]. It's apparent that nearly all the causes are instigated on the non-physical process. This includes the shop floor overload which is often due to planning and decision making problem in the upstream. As the production activities are driven by customer order, this means that the customer 'plays a central role in the production system and the production control system' in the ETO companies.

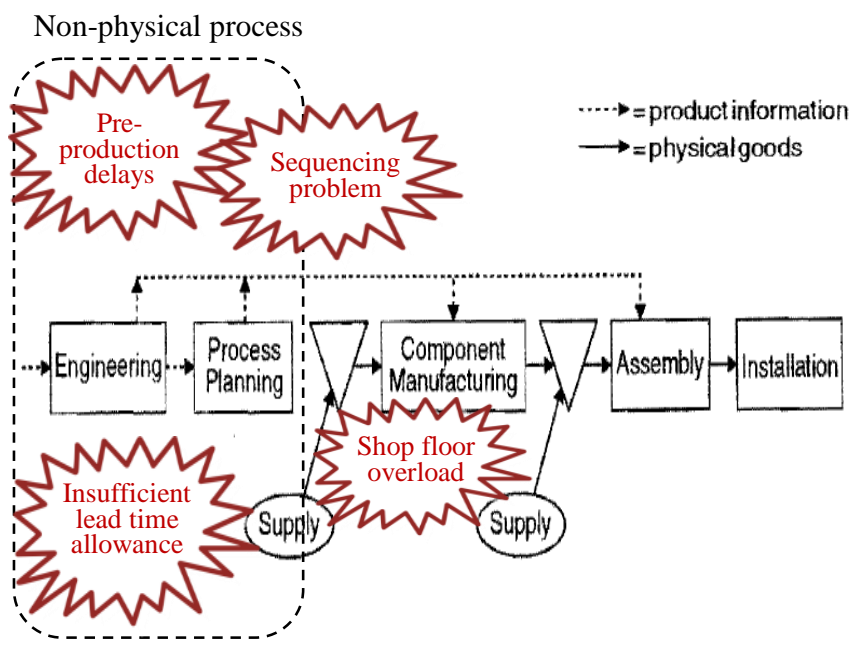

Figure 2: Global flow of goods for ETO production

\subsection{Introducing Quick Response Manufacturing}

Manufacturing Management literature has shared many paradigms with the aim of helping the companies to address the challenge of maintaining competitive in the globalised world [15]. Among the studies of time-based competition (TBC) paradigms [16] and the summary presented in Table 2 showed that QRM is well-suited for ETO manufacturer with the three characteristics ie. high-mix, low volume and custom-engineered [6]. It is able to distinguish some logical messages compared to some other common approaches [17]. Pyrek [17] stated that QRM is a method which searches new execution methods and it focuses mainly on time reduction and reserves spare capacity as the main indicator, involves suppliers and buyers in the QRM program. It can be categorized into two contexts: internally and externally. Internally means this time-based competition paradigm reduces lead time for all tasks in a company whereas externally means QRM enhances responsiveness to customer. QRM has benefitted several companies already and has resulted in lead time reductions of $75 \%$ in new product introductions and $90 \%$ to fill orders of existing products [4].

Table 2: Taxonomic Comparison of Manufacturing Paradigms [6]

\begin{tabular}{|l|c|c|c|c|c|c|}
\hline Features & TPS & $\begin{array}{c}\text { Lean/ } \\
6 \sigma\end{array}$ & $\begin{array}{c}\text { Agile } \\
\text { Manufac- } \\
\text { turing }\end{array}$ & $\begin{array}{c}\text { Mass } \\
\text { Customi- } \\
\text { zation }\end{array}$ & $\begin{array}{c}\text { Holonic } \\
\text { Manufac- } \\
\text { turing }\end{array}$ & QRM \\
\hline Customization & & & $\checkmark$ & $\checkmark$ & $\checkmark$ & $\checkmark$ \\
\hline Flexibility & & & $\checkmark$ & $\checkmark$ & $\checkmark$ & $\checkmark$ \\
\hline $\begin{array}{l}\text { Inventory } \\
\text { reduction }\end{array}$ & $\checkmark$ & $\checkmark$ & & & & $\checkmark$ \\
\hline $\begin{array}{l}\text { Lead Time } \\
\text { Organization- } \\
\text { focus }\end{array}$ & & $\checkmark$ & $\checkmark$ & $\checkmark$ & & $\checkmark$ \\
\hline $\begin{array}{l}\text { Quality } \\
\text { Reconfigur- } \\
\text { ability }\end{array}$ & $\checkmark$ & $\checkmark$ & $\checkmark$ & & & $\checkmark$ \\
\hline \begin{tabular}{l} 
Responsive \\
\hline $\begin{array}{l}\text { Waste elimi- } \\
\text { nation }\end{array}$
\end{tabular} & $\checkmark$ & $\checkmark$ & $\checkmark$ & & $\checkmark$ & $\checkmark$ \\
\hline
\end{tabular}

\subsubsection{Exploiting Variability}

Unlike Lean which is in high-volume, repetitive production, and the core tools such as Takt Times and level scheduling are designed to eliminate variability in operations and create better flow [5]. In contrast, high-mix, low-volume and customization environments pose significant challenges due to the presence of two different types of variability [5].

- Dysfunctional variability: Errors, ineffective systems that cause rework, constantly changing priorities; and "lumpy" demand due to poor interfaces between sales and customers.

- Strategic variability: This form of variability is introduced by a company to compete in the market. The ability to serve market with highly unpredictable demand, a large variety of options for customers and offering custom-engineered products.

While Lean techniques aim to eliminate variability in the manufacturing system, the QRM approach is aligned with Lean in getting rid of dysfunctional variability. However, QRM does not eliminate strategic variability, instead it exploits it. This is done by designing the QRM organization to effectively cope with this variability and thrive in the high-customization markets of the future [5]. Hence QRM takes Lean strategy to the next level (Figure 3). This will become increasingly important as customers demand a wider array of options and customized features.

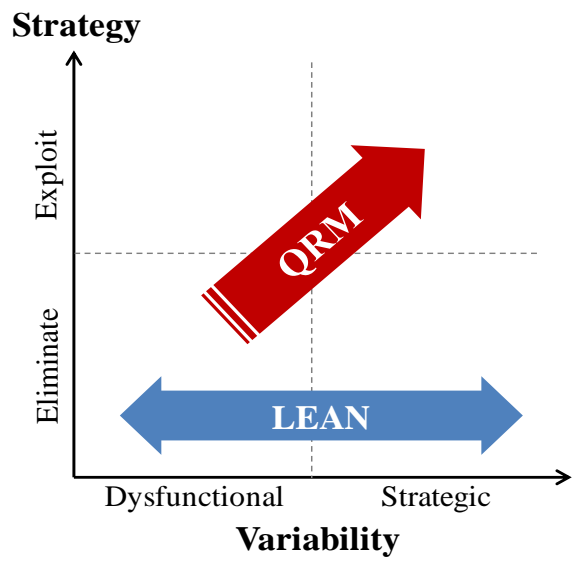

Figure 3: QRM takes Lean to the next level

\subsubsection{Exploiting System Dynamics Principles}

This core concept helps managers understand how system dynamics impacts lead time. A common management misconception is "To get jobs out fast, we must keep our machines and people busy all the time" [4]. This misbelief stems from cost-based thinking as seen from the first graph $4 \mathrm{a}$ in Figure 4: to ensure each resource is used maximally to minimize cost so that you can make do with the least number of resources [18]. So as your resources get busier, you create growing queues for jobs and result long lead time with expediting and other organizational costs - the opposite of the quick response principles. The QRM approach shows that these dysfunctional interactions result in system-wide costs that exceed the cost of the spare capacity. The QRM principle that replaces the traditional belief is quite different, "Strategically plan for spare capacity - the planned loading of your resources should be under $85 \%$, or even under $75 \%$ in very high-variability environments"[4]. 


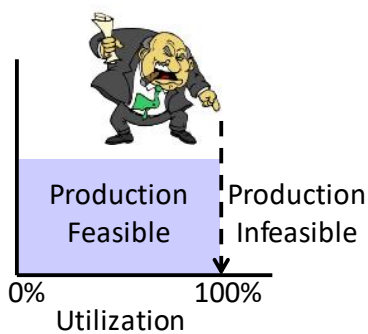

4a. Cost-based View

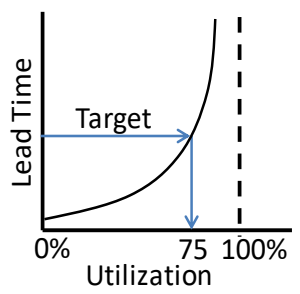

4b. QRM View
Figure 4: Cost-based thinking vs. QRM system dynamics theory

QRM explain the system dynamics theory, which tells us that lead times increase greatly as resources utilizations approach $100 \%$ as shown in Figure 4 second graph $4 b$ [18]. Since in QRM you do not eliminate strategic variability, it is important to design your system to cope with some variability. QRM suggests on a different driving metric to improve manufacturing: lead time. Proponents of this philosophy believe that by reducing the time it takes to produce a product from order to delivery, total costs go down and quality, delivery, and flexibility all improve. The argument runs as follows. If all the work-in-process inventories are minimized in a manufacturing system, problems become easier to be identified, which lead to process and product quality improvement opportunities increase. The metaphor presented in this regard is that of water tides in a pond. If inventories are representing water and stones/rocks in the bottom of the pond are exemplifying quality problems, reducing the volume of water always induces the presence of stones and hence become more likely to get removed. Similarly, since lead-time reduction involves elimination of non-value added chunks of time, it tends to minimize or remove all kinds of waste and thus reduces cost [19]. Nevertheless, the research question posed in this paper is 'How suitable is QRM to improve company delivery performance in an ETO company, such as precision parts manufacturer and, what other operational outputs are affected positively a result of its implementation?'

Suri [20] stated that an effective strategy needs to be supported by a precise methodology and appropriate tools. Therefore, the QRM strategies that are supported by some means and techniques or activities have been defined in the transformation plan as described in Methodology section.

\section{Methodology}

The literature review presented the different levels of customization and that ETO companies manufacture the purest form. The comparison among manufacturing paradigms shows the suitability of QRM in the ETO environment. The literature has also shown that ETO companies is enclosed in the dynamic, uncertain and complex market that causes moving bottlenecks, planning and scheduling issue, sequencing problems, pre-production delays and shop floor overload that result in failure to meet the promised due dates. Thus, competitive advantage in such industries can only be gained by pursuing reliable delivery customer orders faster than competitors. Based on this, it seems that QRM provides an ideal solution to ETO companies as it reduces lead time and improves quality that lead to faster and more reliable delivery. This section will bring the information together on ETO and QRM to design a holistic methodology from conceptual framework development to implementation strategy.

\subsection{Case Study - Precision Parts Manufacturer}

Since this paper is about improving delivery performance at ETO company, the selection of a case company must be appropriate and in line with the goal set. A precision parts manufacturer dealing with ETO business was targeted (Figure 5). The main strength of this company is manufacturing highly complex parts based on the customer's specifications.

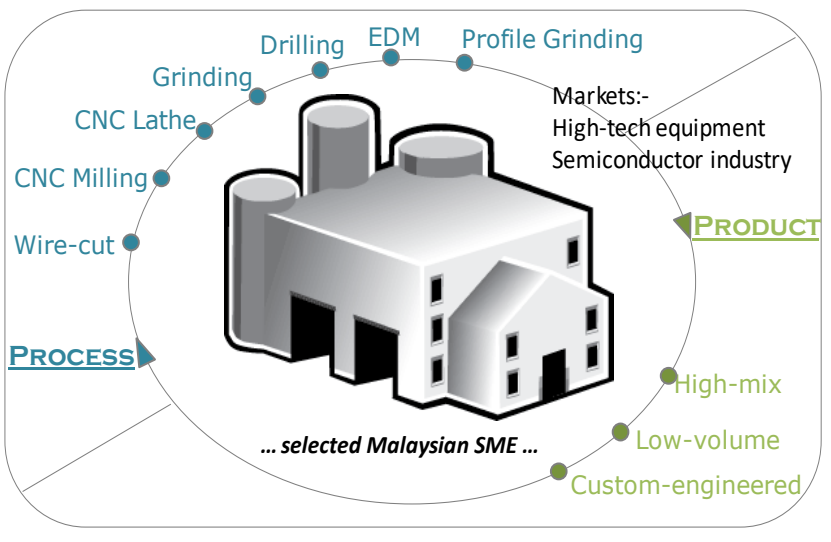

Figure 5: Metal Fabrication Factory with ETO and Job Shop Environment

However, the major challenge facing the high-mix, low-volume and custom-engineered organization is that it has an erratic manufacturing system as compared to the typical mass production. The high-mix and low-volume of customer demands have resulted in jobs that require travelling in different process routes and at different process time. It's also acknowledged that the most common characteristic of many SMEs have within the ETO business model is job shop production. The order fulfillment process can be split into office, manufacturing and shipping department as shown in Figure 6. As depicted in figure 2, the 'office' activities are equivalent to the non-physical processes where the causes eg. sequencing problem, pre-production delays, etc. lead to the OTD failure are usually found. This gives us an indication directly the focus of research area.

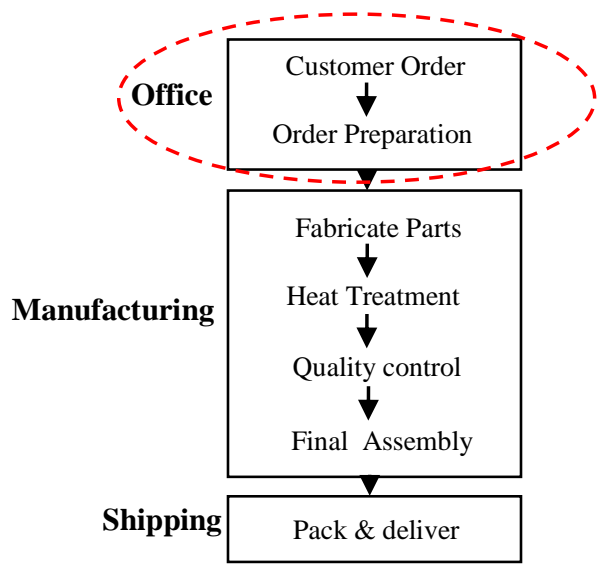

Figure 6: A typical process flow of precision part fabrication

\subsubsection{Dilemma}

The main challenge of such a job shop environment is to fulfill the customer order on time. The late deliveries of goods to customers had led to losses in revenue and business opportunities and directly affect the image and reputation of the company. Figure 7 shows the on time delivery (OTD) records from 2013 to 2016. It clearly shows that the OTD averages are less than $55 \%$, well below the company's target of $90 \%$ with the main contributor of the failure is due to the manufacturing lead time (LT) exceeding the committed delivery of 2 weeks to customers. Figure 8 presented the same years of performance of the exemplary product BI for the case studied company where the actual LT exceeding the target set. In the current scenario it is quite challenging to overcome the company's problem by using the well-known method such as forecasting or built-to-stock method. 


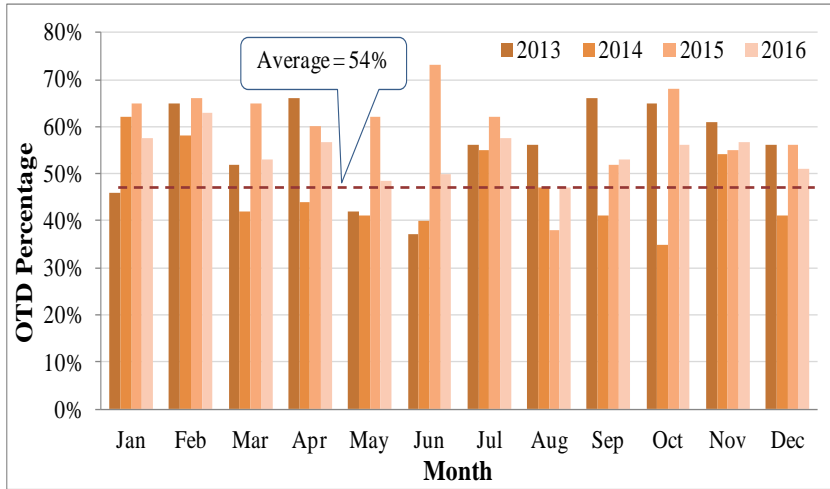

Figure 7: On time delivery from 2013 to 2016

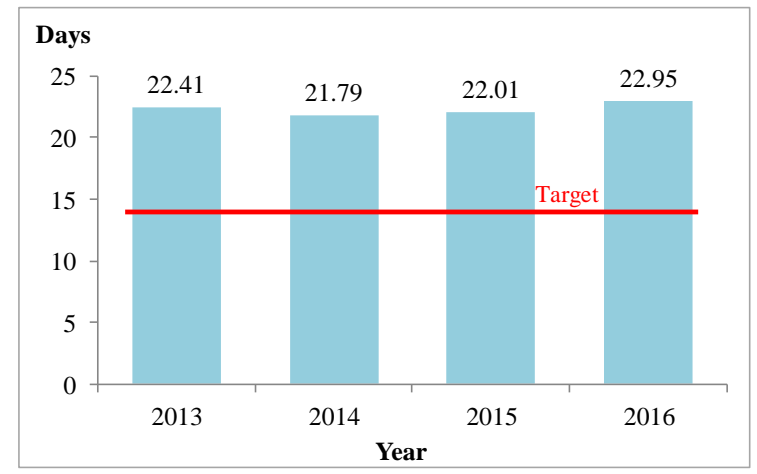

Figure 8: Lead time of exemplary Product BI from 2013 to 2016

\subsubsection{Manufacturing Critical-path Time (MCT) Mapping}

MCT is defined as the time captured in calendar days starting from the customer order, through the critical path, until the delivery of the first end-item of that order [21]. MCT is a simple yet powerful metric to quantify total system-wide waste of an organization. The analysis of this real time measurement help to identify which part or subset of an enterprise is needed for improvement The MCT can be illustrated at best in an MCT Map [22]. Figure 9 illustrates an example of the MCT Map of Product BI in the case studied company [23]. This map provides a clear insight of what is going on in the different process with very little explanation required, for example, we can see that the HP part fabrication takes 22 days and hence the longest critical path. The waiting times that shown proportionally on the map exposes the highest potential areas of lead time reduction.

\begin{tabular}{l}
$\begin{array}{l}\text { Critical Path } \\
\text { (22 days) }\end{array}$ \\
\cline { 2 - 3 }
\end{tabular}

Figure 9: MCT / LT of Product BI

\subsubsection{Why OTD failed?}

In order to diagnose the special causes of not meeting OTD by the QRM team, a Why-why analysis was carried out by a cross functional team of engineers, planning and operations executives. Figure 10 shows the why-why analysis result that enabled the team to recognise and consent on the areas for improvement. The team identified strongly with the issue surrounding the interaction between office and manufacturing. However, the 'proper' interaction process relies on the quick information flow of machine utilization level that helps to make strategic decision. Therefore, this profound gap needs to be rectified with an appropriate material flow control (MFC) mechanism supported by a real-time monitoring system. Lödding[24] classified MFC mechanism as a method of generating order and method of releasing order. In this paper, the issue is more related to the method of releasing order meaning determines the point in time after which a production is allowed to process an order.

\begin{tabular}{|c|c|c|c|c|}
\hline $1^{\text {st }}$ Why & $2^{\text {nd }}$ Why & $3^{\text {rd }}$ Why & $4^{\text {th }}$ Why & $5^{\text {th }}$ Why \\
\hline $\begin{array}{l}\text { Production } \\
\text { unable to } \\
\text { compete the } \\
\text { job on time }\end{array}$ & \begin{tabular}{|c|} 
Some depart- \\
ments took \\
longer time (vs \\
plan) to pro- \\
cess the job \\
(=long MCT)
\end{tabular} & $\begin{array}{l}\text { High WIP } \\
\text { caused long } \\
\text { queue in the } \\
\text { departments }\end{array}$ & $\begin{array}{c}\text { Machines are } \\
\text { fully loaded in } \\
\text { the depart- } \\
\text { ments especial- } \\
\text { ly in critical } \\
\text { process }\end{array}$ & \begin{tabular}{|c|} 
Lack of proper \\
interaction \\
between \\
'Office'\& \\
'Manufacturing' \\
department \\
within the \\
company \\
\end{tabular} \\
\hline & 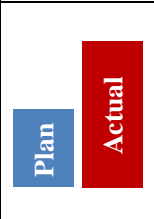 & $\begin{array}{l}9 \text { Cycle time } \\
0 \\
0 \\
0 \\
0 \\
0\end{array}$ & $A$ & \\
\hline
\end{tabular}

\subsubsection{QRM Framework}

Deros et al. [25] suggested that a framework is a set of simplified theoretical principles and practical guidelines which is easy to understand, efficient and can be implemented. A strong conceptual framework captures something real and does this in a way that is easy to remember and apply [26]. It is believed that a sound framework can assist and provide a guide in the implementation process [27]. Therefore, the QRM implementation framework was developed by conducting case studies in a SME in Malaysia is shown in Figure 11. The integrated Material Requirements Planning (MRP) system to be developed to address the $4^{\text {th }}$ and $5^{\text {th }}$ issue from the why-why analysis (Figure 10) ie. i) integration between office and manufacturing and ii) 'proper' interaction process through real-time information flow of machine utilization level that serve as a MFC mechanism and provide a sound basis to the team for making strategic decision swiftly.

\subsubsection{Lead Time Reduction Approach}

Principle (Queuing Delay) provides practical scientific relationships such as the "VUT equation" [28], where the delay due to queuing is equal to a variability factor multiply by utilization factor multiply by effective process time as shown in eq. (1). A corollary to the expression in eq. (1) is the Total Cycle Time (CT) as defined in eq. (2)

Delay $=\mathrm{V} \times \mathrm{U}$ x T

Cycle Time $=$ VUT $+\mathrm{T}$

where: $\quad V=$ Variability factor

$\mathrm{U}=$ Utilization factor

$\mathrm{T}=$ Raw Process Time 


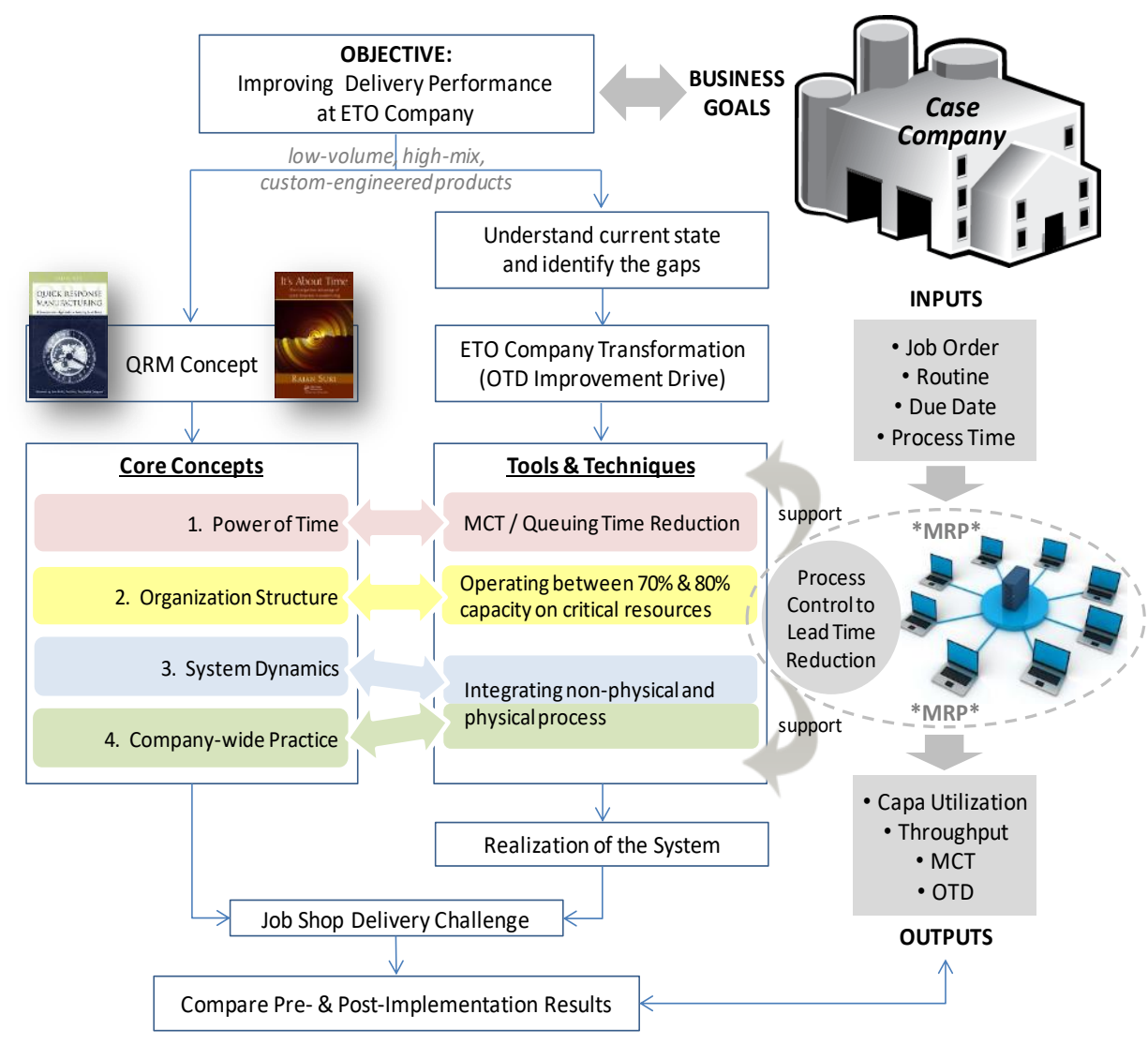

Figure 11: QRM Implementation Framework

The first insight we can get from the VUT equation is that variability and utilization interact. High variability (V) will be most damaging at stations with utilization (U), particularly at bottlenecks. Therefore, reducing queuing delay can be done through a combination of activities that lower utilization and /or reduce variability. We can draw additional insights through the results of Operating Curve (OC) presented in Figure 12 [29][30]. The utilization will be proportional to $u / 1-u$, where $\mathrm{u}$ is the capacity utilization. This means that as utilization approaches $100 \%$, CT will approach infinity. The variability factor is a function of both arrival and process variability, as measured by the CV's of interarrival and process times. The variability is generally proportional to the Squared Coefficient of Variation (SCV) capturing the variation of the interarrival times $C_{a}^{2}$ and the process times $C_{e}^{2}$. Figure 6 shows a plot of OC for three different levels of variability: low, medium and high. A full treatment of CT (Queuing Theory) is far beyond the scope of this paper, but at a high level, the three possible lead time reduction approaches can be considered as shown in Table 3.

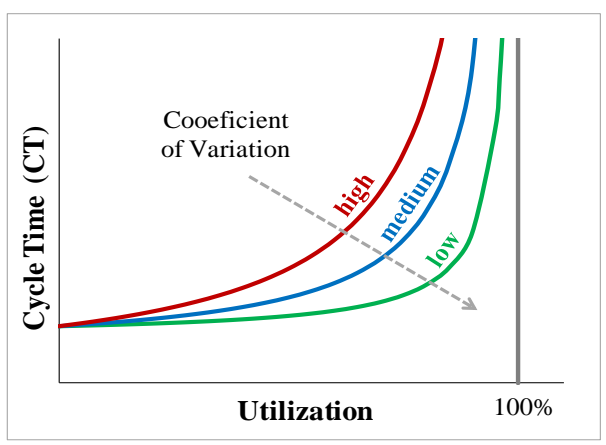

Figure 12: OC - Impact of Utilization and Variability on CT
Table 3: Lead time reduction strategies

\begin{tabular}{|c|c|c|c|}
\hline & Variability (V) & Utilization (U) & Raw Process Time (T) \\
\hline Factor & $\left(\frac{c_{a}^{2}+c_{e}^{2}}{2}\right)$ & $\left(\frac{u}{1-u}\right)$ & $\begin{array}{c}=\text { standard time required } \\
\text { to process a job }\end{array}$ \\
\hline $\begin{array}{r}\text { Alter } \\
\text { solu }\end{array}$ & $\begin{array}{l}\text { Reducing variabil- } \\
\text { ity of ... } \\
\text { - } \text { availability } \\
\text { - } \text { setup \& repair } \\
\text { time } \\
\text { - arrivals } \\
\text { - } \text { etc... } \\
\end{array}$ & $\begin{array}{l}\text { Reducing utilization } \\
\text { by... } \\
\text { - decreasing output } \\
\text { - increasing capacity } \\
\text { - increasing availa- } \\
\text { bility } \\
\text { - etc... }\end{array}$ & 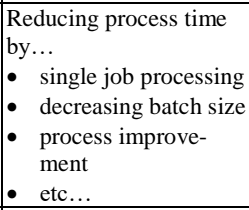 \\
\hline Approach & $\begin{array}{c}\text { LEAN to eliminate } \\
\text { the dysfunctional } \\
\text { variability }\end{array}$ & $\begin{array}{l}\text { QRM to exploit the } \\
\text { strategic variability }\end{array}$ & $\begin{array}{l}\text { QRM / DFM to improve } \\
\text { or redesign the process }\end{array}$ \\
\hline $\begin{array}{l}\text { Analy } \\
\text { Discu }\end{array}$ & \multicolumn{2}{|c|}{ 3.1.5.1. - Figure 13} & 3.1.5.1. - Figure 14 \\
\hline
\end{tabular}

\subsubsection{Change Variability, Utilization and Raw process Time}

Figure 13 presents the performance analysis through Operating Curves of product BI. The graph exhibits that LT increases with utilization and with variability as a growing pace, demonstrated by the increasing distance between the consecutive curves. It shows that utilization has a larger effect on LT than variability, using the current operating point ' $A$ ' (dotted arrows). The LT decreases from 22.3 to 14 days (OTD target) is enabled by utilization reduction from $90 \%$ to $84 \%$ (by $7 \%$ ) or $\mathrm{CV}$ reduction from 1.11 to 0.65 (by $41 \%$ ). However, reducing the CV to either 0.65 or 0.32 to achieve the OTD target at the desired utilization of $90 \%$ and $95 \%$ respectively is a challenging task due to the unavoidable dysfunctional variability in this job shops environment. Hence, we can only rely on QRM principle to exploit the strategic variability through capacity management. Figure 13 also illustrates the impact of increasing variability. In this figure we illustrate what hap- 
pens to two systems that are identical except that one has a $C V$ of 0.65 and the other has a $C V$ of 1.11. By the Queuing Delay Principle, the delay will be nearly two times higher for any given level of utilization in the latter system than in the former [27]. But, as we see from Figure 8, this has the effect of making delay in the system with $C V=1.11$ "blow up" much more quickly. Hence, if we want to achieve the same level of delay in these two systems, we will have to operate the system with $C V=1.11$ at a much lower level of utilization than we will be able to maintain in the system with $C V=0.65$.

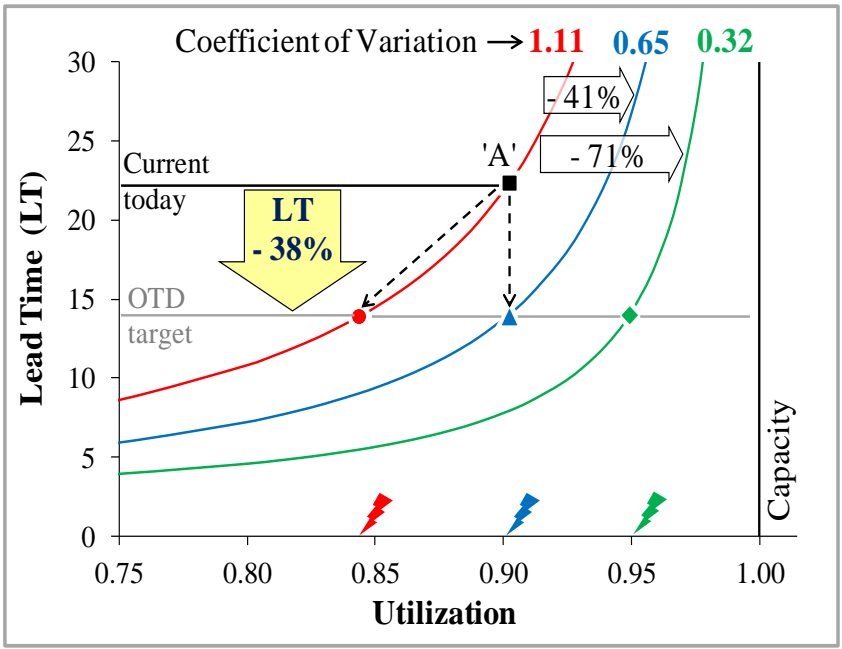

Figure 13: LT improvement analysis through reducing V and $\mathrm{U}$

Reducing raw process time (T) can be another $\mathrm{LT}$ reduction strategy as illustrated in Figure 14. The graph shows time reduction from 2 to 1.25 days (by 38\%) and not 1.5 days (by 25\%). However, improving raw process time by $25 \%$ is more practical in the short term, in which the company can consider to control the capacity usage at $88 \%$ (with only minor drop of current utilization $90 \%$ ) at the same time in order to secure more business from customers with a commitment of shorter LT. However, this approach require process redesigning that may not be practical in the high-mix and custom-engineered environment where you are receiving the new and different job orders most of the time.

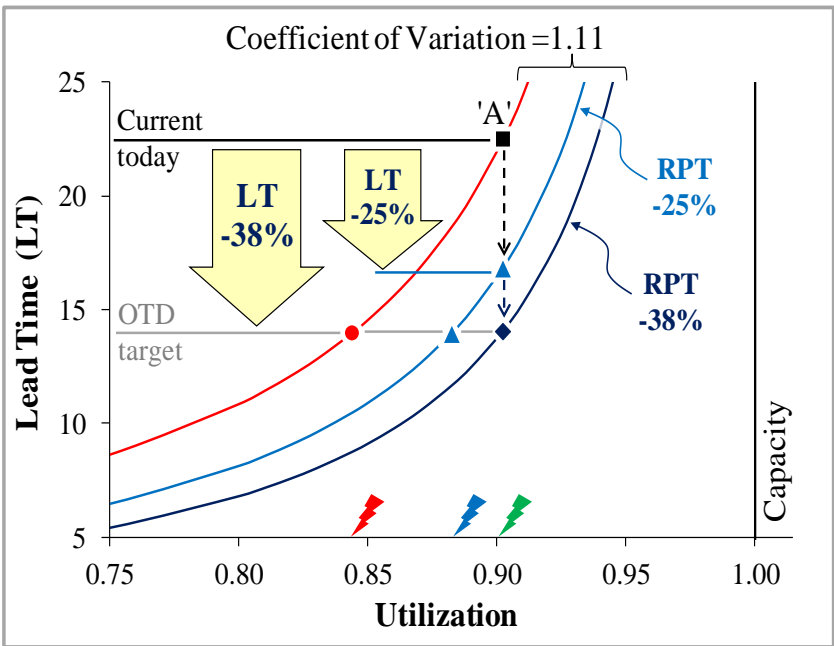

Figure 14: $\mathrm{LT}$ improvement analysis through reducing $\mathrm{U}$ and $\mathrm{T}$

\section{Results and Discussions}

In the development of an integrated QRM Implementation framework, the focus is on ensuring the simultaneous development of the MRP system with the aim that the company simultaneously tackles both the 'organization structure', 'system dynamics' and 'company-wide practice' element of the business. A conceptual framework was initially developed with the author team then embarked on a series of iterative development such as simulation modelling in an attempt to evaluate its effectiveness and suitability to ETO environment. The execution of MRP enabling utilization based control (UBC) mechanism in an overall QRM framework is illustrated in Figure 17. When the received order converted into a job in the system, the real-time capacity utilization can be estimated through the WIP in the production pipeline versus the total capacity available. The utilization level of each process can be tracked by office and manufacturing department to check the availability of the capacity before deciding to process the new order in-house or outsource to avoid overload at the bottleneck process. The relative output performances after implementing QRM are presented in the following.

\subsection{MCT Mapping and Lead Time}

Actions to improve the delivery performance are in place and Figure 15 shows the MCT of the exemplary BI product before and after utilization control mechanism is initiated. Figure 16 demonstrates the impact of the MCT measures introduced to the system and how through continuous incremental improvement, the company is progressively moving towards its 14 days lead time target. A drop of $22 \%$ was seen following the UBC implementation with lead time dropping from 22 days to 17.2 days on average.

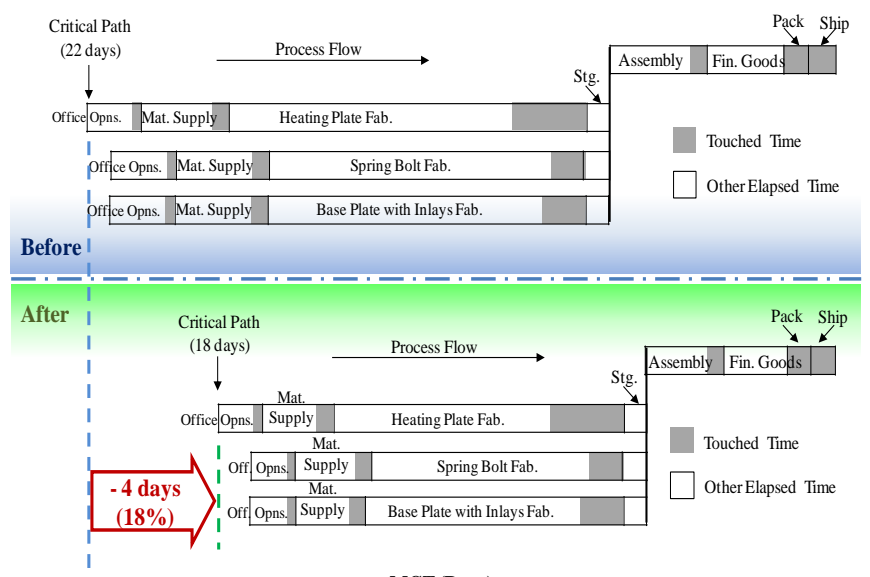

MCT (Days)

Figure 15: MCT comparison for BI product before and after QRM implementation

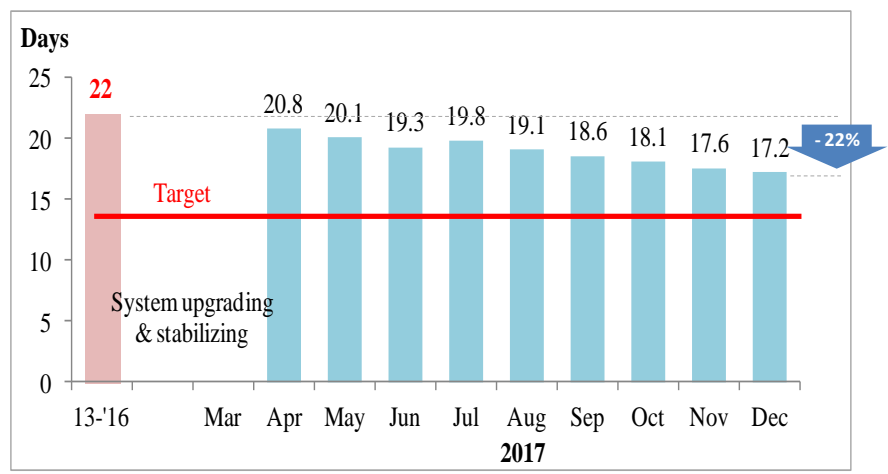

Figure 16: Lead time for BI product after QRM implementation 


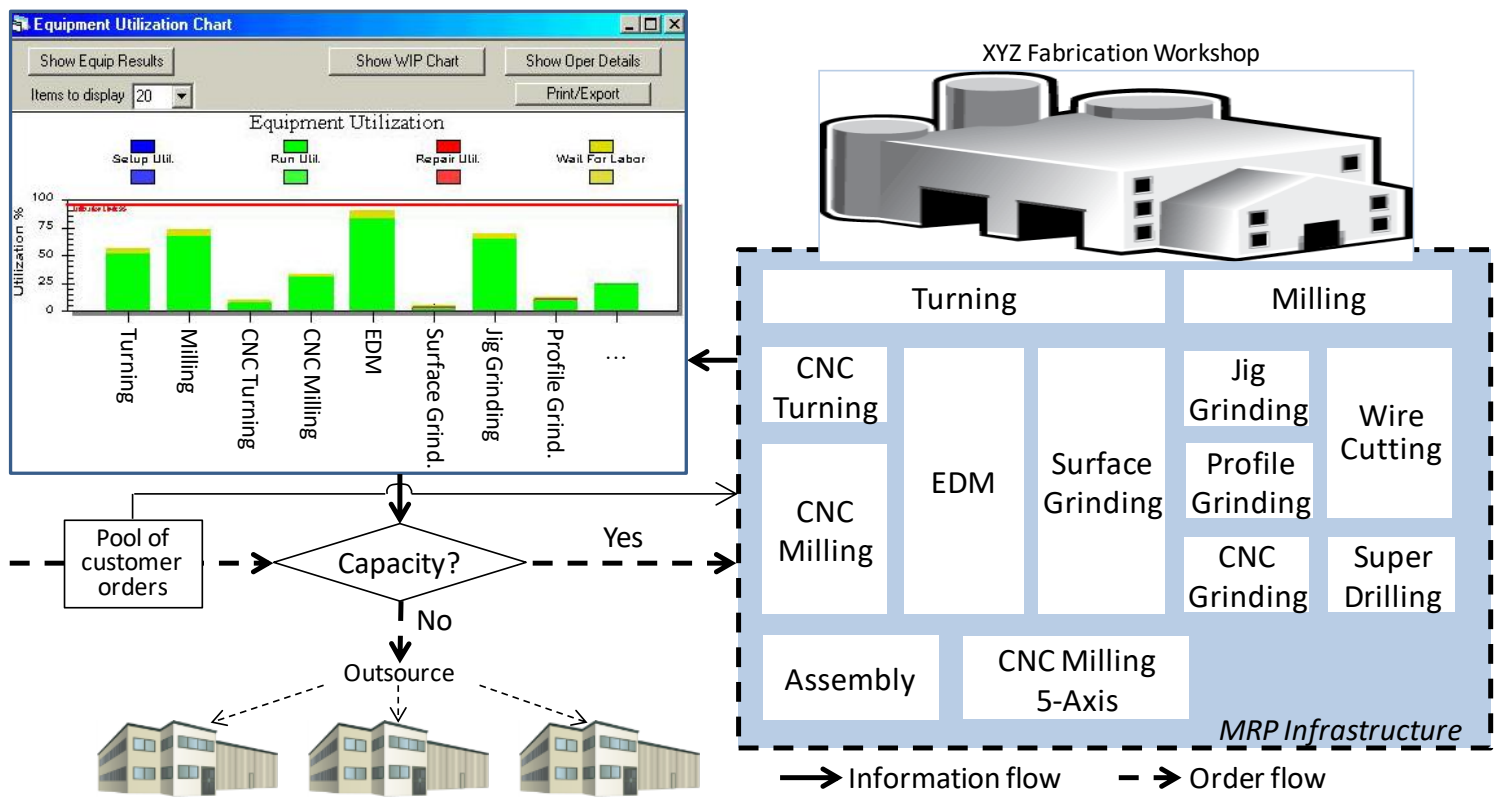

Figure 17: QRM utilization based material control execution model

\subsection{OTD and Bottleneck Utilization}

OTD has improved with a increase from around 50\% in April to $71 \%$ in December (Figure 18) while utilization at critical resources was moving towards the control level of $85 \%$ (Figure 19) which suggests that a simultaneous improvement in both measurements as a result of implementing UBC mechanism.

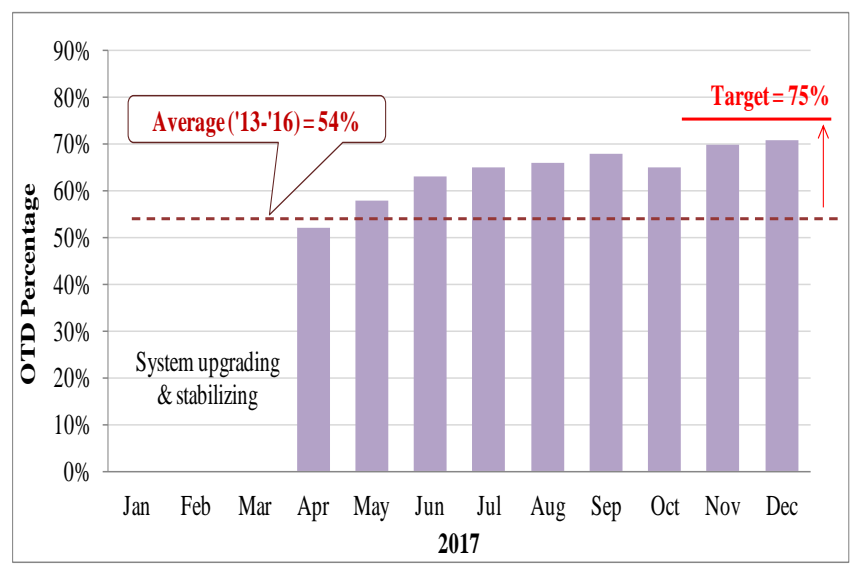

Figure 18: OTD trend for BI product after QRM implementation

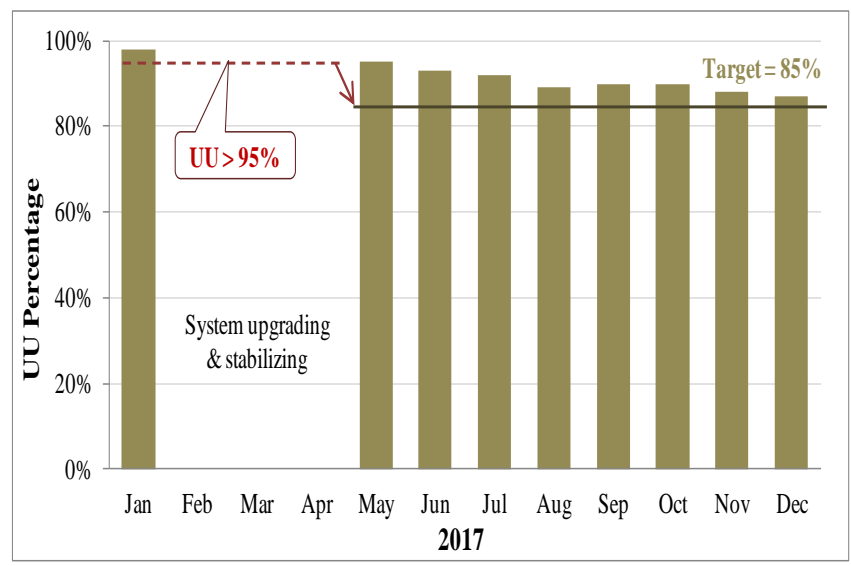

Figure 19: Utilization control at the critical resource in the shop floor

\subsection{Throughpu}

Similarly, improvements were seen in the 'throughput' where the output performance increased by $42 \%$ from 1047 orders received per month in 2015-2016 to monthly orders of 1487 in 2017 (May - December) as presented in Figure 20. To further support the effectiveness of QRM implementation, Table 4 summarizes the comparison of workforce productivity performance. In general, the result shows an increase of job order per head count without additional capital investment in the company. The slight increase of personnel is due to man power optimization in office and manufacturing to ensure no staff is over loaded like the way the capacity utilization is being managed.

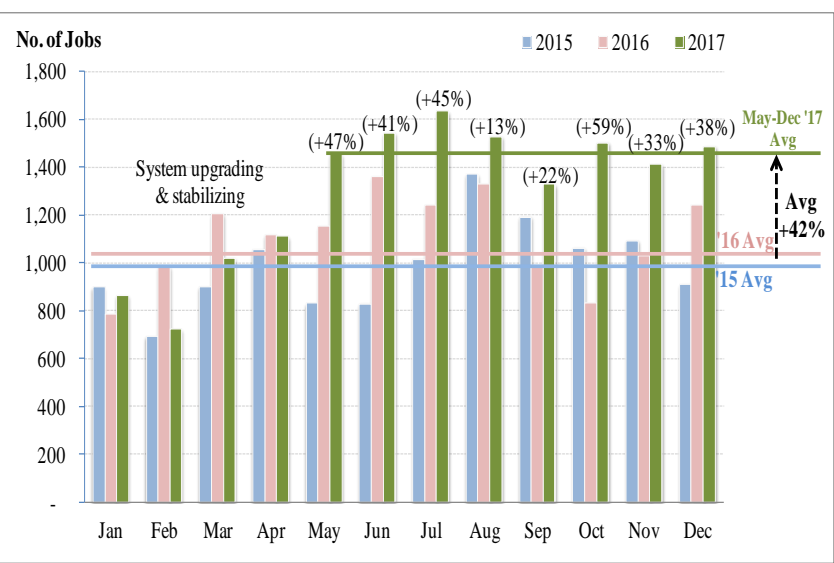

Figure 20: Comparison of throughput pre- and post-QRM implementation

Table 4. Comparison of workforce productivity performance

\begin{tabular}{|l|c|c|c|}
\hline \multicolumn{1}{|c|}{ Year } & '15-'16 & $\mathbf{2 0 1 7}$ & Difference \\
\hline Capacity & \multicolumn{2}{|c|}{ No change } & - \\
\hline $\begin{array}{l}\text { Headcount: Office + Manufactur- } \\
\text { ing direct labor }\end{array}$ & 54 & 58 & $+7 \%$ \\
\hline Average job orders per month & 1047 & 1487 & $+42 \%$ \\
\hline $\begin{array}{l}\text { Average job orders per head } \\
\text { count }\end{array}$ & 19.3 & 25.6 & $+33 \%$ \\
\hline
\end{tabular}




\section{Conclusion}

This paper has described through a case study the implementation of QRM framework based on exploiting the variability and system dynamics principles for ETO operations improvement. QRM is a manufacturing control strategy that focuses on reducing lead time to improve company performance. Through its concurrent focus on attempting the integration issue between the office and manufacturing resulting in shop floor overload and long lead time, the company was able to move towards its OTD target of ensuring $75 \%$ was consistently met at the $1^{\text {st }}$ phase. By integrating office and manufacturing through MRP, the company was able to focus quickly on pre-production planning as being the major contributor for long queuing in production. Long lead times were considered the major cause of the company missing its $85 \%$ OTD resulting in unsatisfied customers. This focus immediately led to the QRM team discovering the high utilization at the critical capacity (moving bottleneck) that adversely affected the performance of their internal operations. Whilst the company has not achieved its first phase OTD and lead time target, the trend shows very promising signals that both targets are likely to be met soon provided the desired level of capacity loading applied to the project is maintained or further reduced.

In answering the question 'How suitable is QRM to improve company delivery performance in an ETO company, such as precision parts manufacturer and, what other operational outputs are affected positively a result of its implementation?' then the following conclusions can be made.

Results showed that just starting with QRM might not result in dealing with the root cause of low delivery performance. QRM concepts provide ideas to search for improvement opportunities, but, in the case of this selected ETO company, it would not immediately solve their biggest problem. Company need to obtain more insight reason in what is causing their low performance in order to decide what improvement method is best to be used. At this ETO company, its problems were caused by lacking of organizational integration and real-time information flow from production that lead to shop floor overload.

To solve this shop floor overload problem, QRM does provide a solution for the long term. The application of QRM concepts shows that it can be effectively delivered in to ETO operations by concurrently integrating office and manufacturing using MRP to enhance the decision making of job release to the shop floor. Five decision levels are used: order received, job entry stage, capacity utilization monitoring, dispatching rules and decision making (inhouse or outsource). The outputs performance has directly boosted the confidence level to finish the incoming customer orders with the shortest time possible, making it a viable strategy with competitive advantage to be considered by companies that want to secure more business. Future research might focus on the possibilities of adapting QRM in different ETO companies.

\section{Acknowledgement}

This work was supported by the Minister of Higher Education, Malaysia under the grant FRGS/1/2015/TK03/FKP/02/F00278 and appreciation to Universiti Teknikal Malaysia Melaka (UTeM) for supporting this study.

\section{References}

[1] Bertrand, JWM, \& Muntslag, DR (1993), Production control in engineer-to-order firms. International Journal of Production Economics 30-31, 3-22.

[2] Stalk, GJr (1988), Time-The Next Source of Competitive Advantage. Harvard Business Review July-August, 41-51.

[3] Hendry, C (2010), Product customization: an empirical study of competitive advantage and repeat business. International Journal of Production Research 48(13), 3845-3865.
[4] Suri, R (1998), Quick Response Manufacturing: A Company-wide Approach to Reducing Lead Time. New York, NY: Productivity Press.

[5] Suri, R (2010), It's About Time. The Competitive Advantage of Quick Response Manufacturing. New York, NY: Productivity Press.

[6] Nambiar, AN (2010, March), Modern Manufacturing Paradigms A Comparison. Paper presented at the International MultiConference of Engineers and Computer Scientists, Hong Kong.

[7] Amaro, G, Hendry, L, \& Kingsman, B (1999), Competitive advantage, customization and a new taxonomy for non make-to-stock companies. International Journal of Operations \& Production Management 19(4), 349-371.

[8] Knol, RH (2012), Using QRM to improve delivery performance at Larsen Premium Precision Parts: A case study to investigate the usability of QRM (Unpublished master's thesis). University of Groningen, Netherlands

[9] Lampel, J, \& Mintzberg, H (1996), Customizing customization. Sloan Management Review 38, 21-30.

[10] Gupta, D, \& Benjaafar, S (2004), Make-to-order, make-to-stock, or delay product differentiation? A common framework for modeling and analysis. IIE Transactions (Institute of Industrial Engineers) $36(6), 529-546$

[11] Altendorfer, K, \& Jodlbauer, H (2011), An analytical model for service level and tardiness in a single machine MTO production system. International Journal of Production Research 49(7), 18271850.

[12] Hopp, WJ, \& Spearman, ML (2008), Factory Physics (3rd ed.). New York, NY: McGraw-Hill.

[13] New, CC (1977), Managing the manufacture of complex products: coordinating multicomponent assembly. London: Business books communica europe.

[14] Muntslag, DR (1993), Managing customer order driven engineering : an interdisciplinary and design oriented approach. Eindhoven: Technische Universiteit Eindhoven.

[15] Gunasekaran, A (1999), Agile manufacturing: A framework for research and development. International Journal of Production Economics $62,87-105$

[16] Filho, MG, \& Saes, EV (2013), From time-based competition (TBC) to quick response manufacturing (QRM): the evolution of research aimed at lead time reduction. International Journal of Advanced Manufacturing Technology 64(5), 1177-1191.

[17] Pyrek, R (2010), Quick response manufacturing description. Tarnow Research Papers Collection 2(16), 109-115.

[18] Harding, L (2002), QRM - An Enabler on the Road to Agility? Quick Response Manufacturing - Part 1. Control, May, 20-22.

[19] Uzair, KM (2001), Development of a Framework for Comparing Performance Improvement Programs (Unpublished master's thesis) Massachusetts Institute of Technology, United States.

[20] Suri, R (2011), Beyond Lean: It's About Time! Technical Report. Center for Quick Response Manufacturing. University of Wisconsin-Madison.

[21] Suri, R (2014), MCT: Quick Reference Guide. Madison. Wisconsin: Author.

[22] Bong, CS, Chong, KE, \& How, WC (2016, September), Job shop material control based on the principles of quick response manufacturing. IDECON 2016. Proceedings of the $5^{\text {th }}$ International Conference on Design and Concurrent Engineering, Langkawi, Malaysia. Melaka: Universiti Teknikal Malaysia Melaka.

[23] Bong, CS, \& Chong, KE (2017, July), Applying quick response manufacturing to exploit variability and reduce lead time in the job shops. ISoRIS 2017. Proceedings of the International Symposium on Research in Innovation and Sustainability. Malacca, Malaysia.

[24] Lödding, H (2013), Handbook of Manufacturing Control : Fundamentals, Description, Configuration. New York: Springer.

[25] Deros, BM, Yusof, SM. \& Salleh, AM (2006), A benchmarking implementation framework for automotive manufacturing SMEs. Benchmarking: An International Journal 13(4), 396-430.

[26] Wikipedia, http://en.wikipedia.org/wiki/Framework.

[27] Yusof, SM, \& Aspinwall, E, (2000), A conceptual framework for TQM implementation for SMEs. The TQM Magazine 12(1), 31-36.

[28] Hopp, WJ (2008), Supply Chain Science, Chicago: Waveland Press.

[29] Hopp, WJ, and Spearman, ML (2001), Factory Physics (2 ${ }^{\text {nd }} E d$ ), New York: Irwin McGraw Hill.

[30] Wu, K, (2005, February), An Examination of Variability and Its Basic Properties for a Factory. IEEE Transactions On Semiconductor Manufacturing 18(1), 214-221. 